\title{
A Comparison Between Virtual Patient and Peer-Assisted Learning in Teaching Basic Medical Knowledge and Skills
}

\author{
Lukas Seifert, Arda Manap, Jasmina Sterz, Ferdinand Gerlach and Robert Sader \\ Goethe University Frankfurt, Frankfurt, Germany \\ lukasbenedikt.seifert@kgu.de \\ manap.arda@gmail.com \\ jasmina.sterz@kgu.de \\ gerlach@allgemeinmedizin.uni-frankfurt.de \\ r.sader@em.uni-frankfurt.de \\ DOI: 10.34190/EJEL.20.18.1.004
}

\begin{abstract}
The Studentische Poliklinik is Germany's first student-run free clinic. Prior to fulfilling clinical obligations there, students must complete an extensive peer-assisted learning program (PAL). Due to capacity constraints, a web-based learning program involving virtual patients has been launched. The aim of this study was to evaluate and compare the effectiveness of Virtual Patient Learning (VPL) vs. PAL in the acquisition of basic medical knowledge and skills. Forty undergraduate medical students $(m=9 ; f=31)$ in their third year were randomly assigned to either the PAL $(n=20)$, or VPL $(n=20)$. Short-term (after each seminar) and long-term learning retention (after completion of the electives) was measured using a validated theoretical test. Objective structured clinical examinations (OSCE) were used to assess practical knowledge. Additionally, the course itself was evaluated. Differences in theoretical knowledge between students in the PAL and VPL existed over the short term (VPL median $=100 \%$; PAL median $=80 ; p=0.006$ ), but not over the long term (VPL $=94.17 ; \mathrm{PAL}=95.62 \% ; p=0.617)$. An assessment of practical skills showed no differences in OSCE scores between the two different groups (VPL $=79.30 \%$; PAL $=80.26 \% ; p=0.141)$. Students assessed their learning experience and the comprehensibility of seminars as either "very good" or "good". Basic medical knowledge and skills can be taught as effectively using VPL as PAL. Given the cost-effectiveness, high reproducibility and freedom of time and place, VPL should be performed more often when teaching family medicine in student-run free clinics. Ultimately, this may result in enhanced treatment quality and patient satisfaction.
\end{abstract}

Keywords: Student-Run Free Clinic, Peer-assisted Learning, Web-based learning, Virtual Patient, Medical Education, Family Medicine

List of abbreviations:

PAL - Peer-assisted learning; VPL - Virtual Patient learning; SP - Studentische Poliklinik; SRFC - Student-run Free Clinic; OSCE - Objective Structured Clinical Examination

\section{Introduction}

Ongoing economization in health care has resulted in less time for clinical teaching (Adili et al., 2013; Marburger Bund, 2017), and acceptance of real patients when teaching clinical skills is declining for ethical reasons. The virtual patient, a computer program that simulates real-life clinical scenarios, is therefore becoming increasingly popular in medical education. Virtual patient learning (VPL) has enjoyed increasing popularity in the fields of education, management of digital patient data and scientific literature for some time now (Ellaway, 2004). In the context of healthcare education, VPL was introduced for the first time in 1991 and since then has increasingly been mentioned in the scientific literature (Kononowicz et al., 2015). According to the Association of American Medical Colleges, VPL represents "a specific type of computer program that simulates real-life clinical scenarios; learners emulate the roles of health care providers to obtain history, conduct a physical exam, and make diagnostic and therapeutic decisions" (Association of American Medical Colleges, 2007). This definition attaches particular significance to understanding clinical reasoning, which is a core skill and one that is of paramount importance in healthcare education (Hege et al., 2018; Higgs et al., 2018; Lateef, 2018). A significant part of the VPL used in medical education therefore focuses on the acquisition of clinical reasoning skills (Kononowicz et al., 2015).

Cook, Erwin and Triola (2010) showed that when used as an additive teaching intervention, VPL is associated with a substantial increase in knowledge, clinical reasoning competence and skills. This is because VPL enjoys considerable advantages compared to traditional teaching formats. For educators, VPL "can provide a way to overcome the reduced student access to real patients" (Consorti et al., 2012). Furthermore, VPL gives students 
the chance to acquire information in a comfortable learning environment and to look up information while working on cases. Moreover, VPL shifts the focus of lectures from a teacher-centered to a learner-centered perspective (Tworek et al., 2010), meaning that students actively perform the actions and make the decisions of a primary caregiver, rather than simply passively attending a lecture (Bryce et al., 1998; Cook, Erwin and Triola, 2010;). The different process also means students are encouraged to take responsibility for their medical decisions, which can increase their motivation. In this context, Gormley, et al. (2011) concluded that although it is challenging for medical students to act as a "clinician" and take responsibility for actual cases, it appears to be the best way to learn. Students can experiment in a safe environment and practice clinical thinking, even though virtual patients are not the same as real patients.

Cook, Erwin and Triola (2010) concluded, "VPL may be noninferior in some instances", which raises the question whether VPL can be considered an alternative to traditional educational methods. In a recent metaanalysis of twelve randomized controlled studies, Consorti et al. (2012) explored this question in more depth and found that in the acquisition of clinical reasoning competencies and skills, VPL was beneficial as a complement, as well as an alternative to PAL.

Despite a considerable number of preliminary publications on VPL, only few studies have been carried out in a randomized and controlled setting (Fleetwood et al., 2000; Janda et al., 2004; Kumta et al., 2003; Triola et al., 2006), and hardly any studies focused on the long-term learning retention of acquired skills. Moreover, we could not find any studies that compared VPL to peer-assisted learning (PAL). In PAL, senior students provide their junior colleagues with teaching and learning support, which has the advantages that trainees often consider peer-trainers to be more approachable than faculty staff, and trainers are more familiar with courses because they have already passed them (Siddiqui et al., 2018). PAL is often used to teach clinical reasoning and practical skills in skills laboratories (Field et al., 2004), and it plays an integral part in so called student-run free clinics (Meah, Smith and Thomas, 2009). It also leads to substantial growth in clinical competencies (Seifert et al., 2015).

A thorough review of the current literature did not reveal any studies investigating the educational outcomes of VPL as an alternative teaching format to PAL in the context of a student-run free clinic project. We therefore conducted this study to find out whether the use of VPL is as effective as a previously described PAL program (Seifert et al., 2015) in the acquisition of clinical reasoning competencies and practical skills. Our hypothesis was that VPL would result in similar educational outcomes.

\section{Methods}

\subsection{Ethics approval and consent to participate}

The study was approved by the Ethical Commission of the University Hospital Frankfurt (Goethe University) and no further approval was required. The study was conducted according to the Declaration of Helsinki (World Medical Association, 2013). All study participants gave their written consent for participation, which they could withdraw at any time.

\subsection{Studentische Poliklinik}

The Studentische Poliklinik (SP) was set up by the Faculty of Medicine of Goethe University Frankfurt and is Germany's first student-organized, physician-supervised family practice for the medically underserved community. Prior to working during clinic hours at the SP, undergraduate medical students have to complete an extensive PAL program (Seifert et al., 2015). PAL covers the most common reasons for consulting a primary care physician (e.g. headache, hypertension, abdominal pain) and trains students to perform basic clinical skills (physical examinations, taking blood samples and medical histories).

\subsection{Study Design}

Forty of the medical students that applied for the SP elective in their first clinical year were randomized to either a peer-assisted learning group (PAL; $n=20 ; f=17 ; m=3$ ), or a virtual patient learning group (VPL; $n=$ $20 ; f=14 ; m=6)$. The groups attended the first and third modules of the SP elective together, but were trained separately in a second module that used either PAL (Field et al., 2007) or VPL (see below), depending on group. In addition, both groups attended regular curricular training consisting of eight physician-led examination classes and basic lectures in surgery, internal medicine, pathology and microbiology during the winter semester of 2016/2017 (October 2016 - April 2017). 


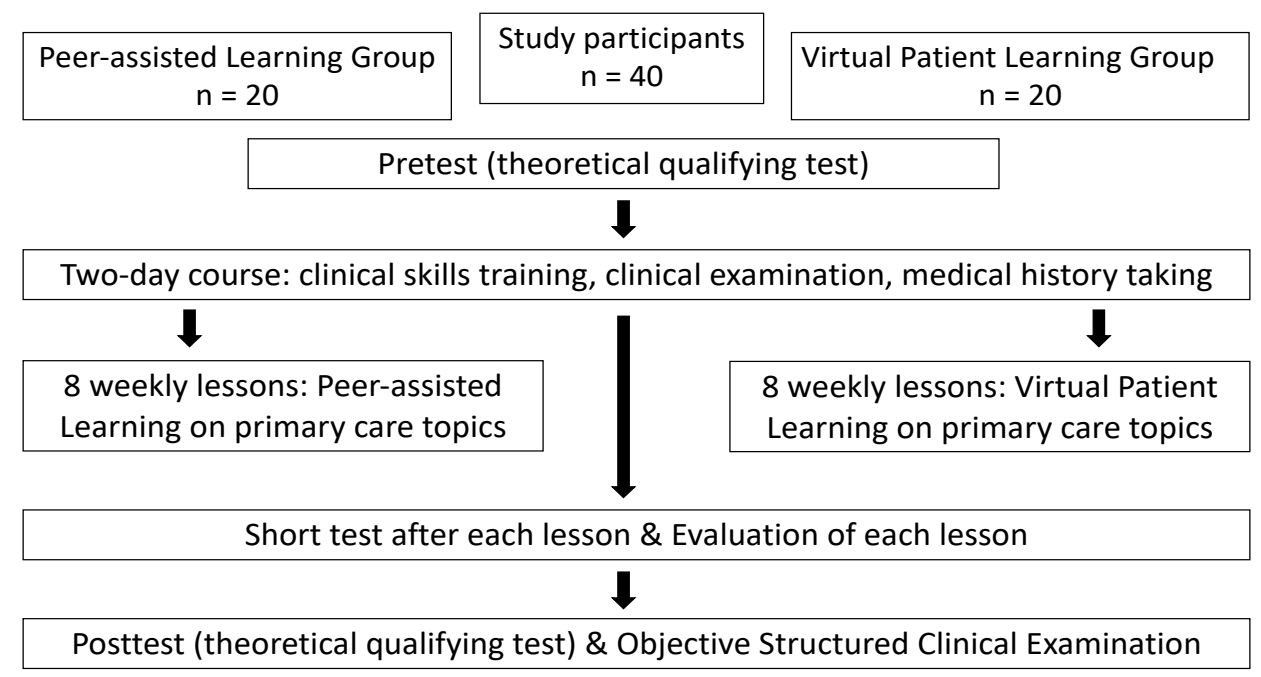

Figure 1: Study Design

\subsection{Structure of the SP elective}

The SP elective consists of three modules (Figure 2) that students have to attend to qualify to work as so-called "juniors" during consultation hours (Figure 2). This elective has been described in greater detail in previous publications (Seifert et al., 2015). The first module for both the PAL and VPL involved a clinical examination, medical history taking and basic clinical skills. The course consisted of six 1.5-hour units on abdominal examinations, cardiac examinations, pulmonary examinations, orthopedic examinations, prenatal care and medical history taking.

The second module was composed of eight weekly, case-based, and symptom-orientated primary care seminars. The aim of this module was to teach the students about clinical appearance, diagnostics and therapy options, as well as clinical reasoning with respect to common primary care topics.

Following theoretical and practical examinations, students worked as "juniors" with more experienced "seniors" in the third module, which was an SP consultation hour. Clinic duties involved medical history taking, physical examinations, and clinical competencies such as taking blood samples, and completing medical documentation. Each patient was seen by a junior-senior team before being presented to a primary care physician for further diagnosis and treatment.

\begin{tabular}{|c|c|c|}
\hline $\begin{array}{l}\text { First module: } \\
\text { Two-day course }\end{array}$ & $\begin{array}{l}\text { Second module: } \\
\text { Eight lessons on } \\
\text { primary care topics }\end{array}$ & $\begin{array}{l}\text { Third module: } \\
\text { Participation in consultation } \\
\text { hours of SP }\end{array}$ \\
\hline $\begin{array}{l}\text { - Clinical skills training } \\
\text { - Clinical examination } \\
\text { - Medical history taking }\end{array}$ & $\begin{array}{l}\text { - Headache } \\
\text { - Diabetes } \\
\text { - Pregnancy }\end{array}$ & $\begin{array}{l}\text { - one consultation hour for } \\
\text { administrative work } \\
\text { - three consultation hours }\end{array}$ \\
\hline Both test groups & $\begin{array}{l}\text { - Lower back pain } \\
\text { - Hypertension } \\
\text { - Anaemia } \\
\text { - Tuberculosis } \\
\text { - Abdominal pain }\end{array}$ & $\begin{array}{l}\text { as a practical trainee } \\
\text { Both test groups }\end{array}$ \\
\hline Peer-assisted Learning Group & & Virtual Patient Learning Group \\
\hline
\end{tabular}

Figure 2: Structure of SP's elective subject 


\subsection{Peer-assisted Learning Group}

The PAL group was taught in groups of up to ten students by four trained peer-tutors (each tutor being responsible for two seminars) every week. Each seminar lasted about two hours and dealt with an important primary care topic (Figure 2) that was presented in a case-based clinical scenario. Patient actors were used to strengthen previously acquired knowledge concerning taking a medical history and performing physical examinations. Students were guided through the clinical cases by the tutor and supported by fellow students, creating a supportive environment that was also rich in feedback. Emphasis was placed on learning clinical reasoning, differential diagnostics and basic therapy options.

\subsection{Virtual Patient Learning Group}

Virtual patient cases created using the Moodle Learning Management System were used to train participants in the VPL (Dougiamas and Taylor, 2003). Every week, students were presented with a virtual patient case (Figure 3) that was identical to the case used in the PAL group. Cases differed only slightly from PAL cases, for example because information on clinical, diagnostic and treatment options were provided in additional textboxes, and multiple-choice questions were used to compensate for the missing interaction with a student tutor (Figure 4). Correct answers were rewarded with motivational feedback and further information on the case, while wrong answers led to constructive feedback and detailed explanations concerning the various choices. VPL cases were enriched with photographs of typical clinical presentations, radiological findings and videos of clinical examinations. Cases had to be completed within one week, and students were free to choose the location and pace of case completion, as well as whether they wanted to work alone or in small groups.
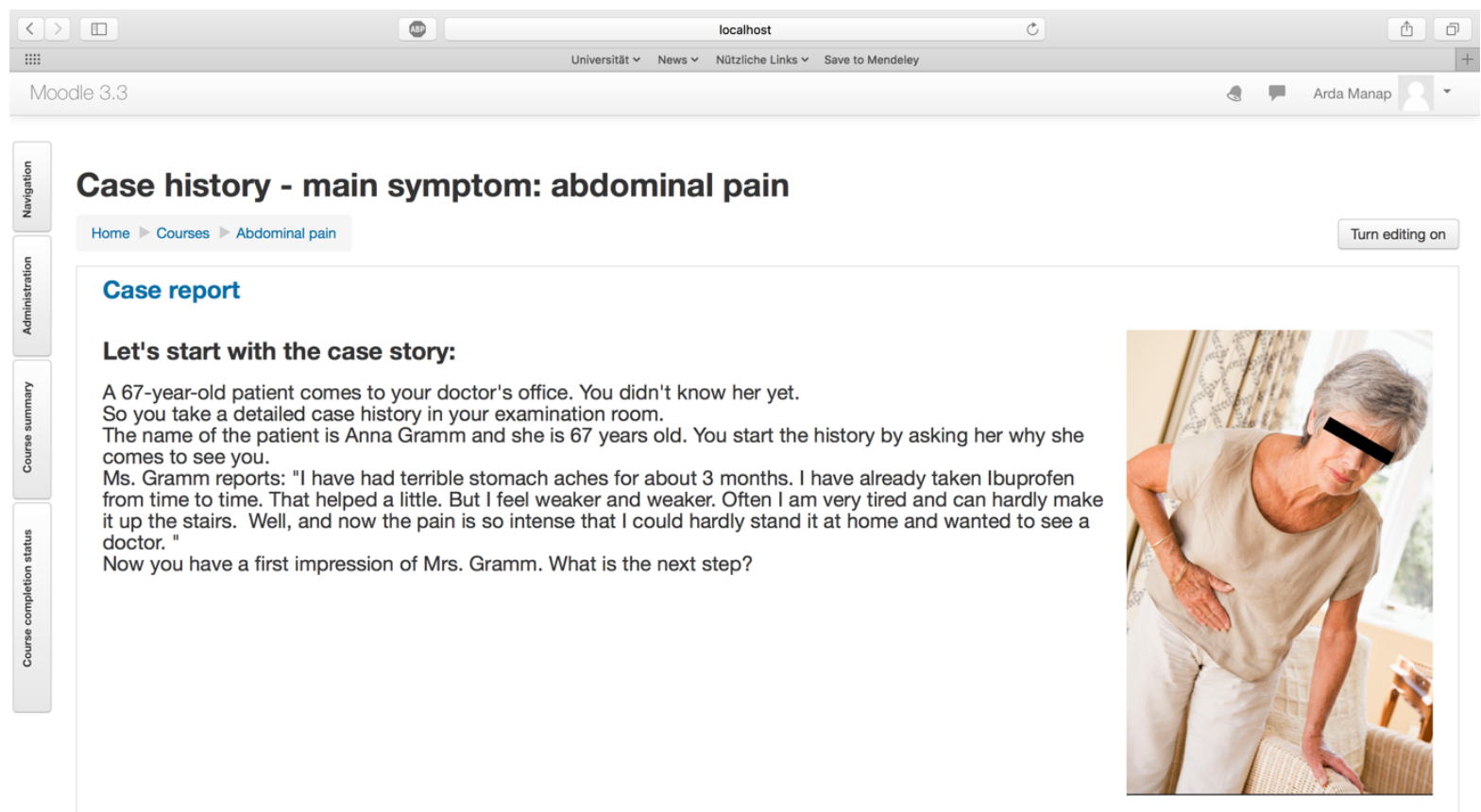

Medical history taking

무

Figure 3: Screenshot of a VPL case with an introductory case report 


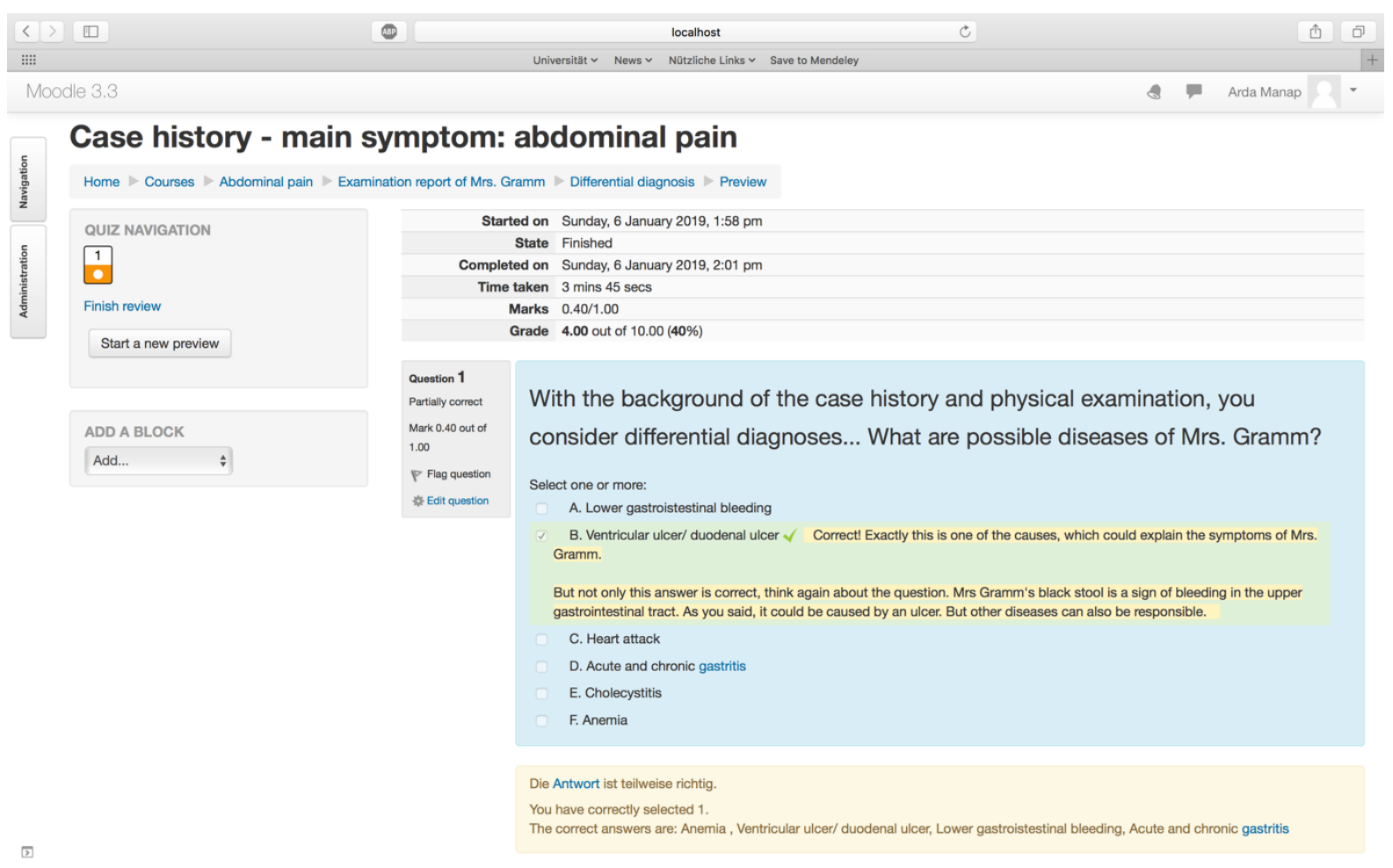

Figure 4: Screenshot of a VPL case including a single-choice question and feedback

\section{Performance measurement}

Four tests were carried out to measure theoretical and practical performance:

1. Long-term theoretical knowledge growth was assessed using 24-item single-choice questions taken from the German Institute for Medical and Pharmaceutical Examination Questions "IMPP" (Supplement). The test covered the learning objectives of the second module and was approved by a group of experts. Both test groups completed this test prior to the start of the elective and six weeks after completion of the second module. The 24 items were based on the primary care topics taught in the second module, and the results for both groups were compared. Furthermore, the post-test was used as a theoretical examination prior to the start of the third module.

2. The test took place in a seminar room. Overall, 90 seconds were allowed for each question, resulting in a total of 36 minutes. The questions were presented in a Power Point format and the students responded online using smartphones or tablets.

3. Short-term theoretical knowledge was assessed using five single-choice questions taken from the German Institute for Medical and Pharmaceutical Examination Questions "IMPP" covering the learning objectives of the recently completed patient case (Figure 5). Students were asked to answer these questions directly after completion of the VPL or PAL case, as applicable. While the PAL group was asked to answer the questions in the seminar room where the course took place, the VPL group had to answer the questions online (at the end of the VPL case seminar). VPL students could move back and forth within the patient case and were subject to no time restrictions. No time limit was set for the PAL students in order to create the same test conditions.

4. Furthermore, students were asked to evaluate their learning experience after each patient case in a five-question questionnaire that used a Likert Scale ranging from 1 = "strongly agree" to $6=$ "strongly disagree" (Table 3).

5. To identify any differences in practical competence, both groups participated in a four-item Objective Structured Clinical Examination (OSCE) six weeks after completing the first two elective modules. This OSCE consisted of one item on history-taking, one on providing feedback, and two on physical examinations. Structured and validated checklists were taken from a pool of checklists which stemmed from the curricular "Examination and Clinical Skills" OSCE used in the third year of medical school (Figure 6). 
1. A 35-year-old driver and chain smoker wakes up at night - for 2 weeks - with severe rightsided headaches, which are repeated in attack form every two hours and last 30-60 minutes. Typical right-sided findings during the attack are conjunctival injection, lacrimation, rhinorrhoea and Horner's syndrome. Which of the following therapeutic measures has the greatest significance here?

A) $\mathrm{O} 2$ inhalation

B) Administration of glycerol trinitrate

C) infraorbital alcohol injection

D) Thermocoagulation of the ganglion stellatum

E) i.v. infusion of valproate

2. What is the least to be expected in migraine?
A) Nasal flow
B) Aphasia
C) Scotomas
D) photophobia
E) Nausea

3. A 49-year-old teacher has been suffering for years at least every other day from a bifrontal headache that lasts for several hours and is oppressive on both sides. It feels like he has a helmet on his head. Nausea or vomiting did not occur, and despite these headaches he could continue to work. Nevertheless, they significantly impaired his quality of life, especially since the usual headaches such as acetylsalicylic acid, paracetamol or ibuprofen are not effective. He smokes about 20 cigarettes a day, probably sleep poorly due to stress, but is otherwise healthy. The clinical-neurological findings are normal, including an eyeground mirroring, as is the blood pressure. Which of the following drug therapies are the most suitable for this headache?

A) Acetylsalicylic acid $100 \mathrm{mg} / \mathrm{d}$

B) Amitriptyline $50-150 \mathrm{mg} / \mathrm{d}$

C) Carbamazepine $400-1600 \mathrm{mg} / \mathrm{d}$

D) oral glucocorticoid therapy (e.g. prednisolone regimen starting at $1 \mathrm{mg} / \mathrm{kg}$ body weight)

E) Indomethacin $50-150 \mathrm{mg} / \mathrm{d}$

4. Which of the following medications is not suitable for the acute therapy of a migraine attack?
A) ASS $1000 \mathrm{mg}$ i.v.
B) MCP $20 \mathrm{mg}$ i.v.
C) Sumatriptan i.n.
D) Propanolol $75 \mathrm{mg}$ p.o.
E) Ibuprofen $600 \mathrm{mg}$ i.v.

5. What symptoms cannot be included in the aura of a migraine?
A) Visual field failures
B) Conjunctival injection
C) Flicker scotomas
D) Scintillations
E) Ophthalmoplegia

Figure 5: Five questions were used after each seminar to assess short-term knowledge retention after VPL or PAL case completion. This is an example of the case history on "Headache". 


\section{Examination of the heart}

Evaluate the student's examination technique during the physical examination.

Student ID:

Part A

\begin{tabular}{|l|c|c|c|}
\hline Checklist physical examination & $\begin{array}{c}\text { not tried } \\
\text { (0) }\end{array}$ & $\begin{array}{c}\text { wrong } \\
\text { (1) }\end{array}$ & $\begin{array}{c}\text { right } \\
\text { (2) }\end{array}$ \\
\hline General Inspection, Thorax, Edema & & & \\
\hline Jugular Vein Inspection ( inconspicuous) & & & \\
\hline Hepatojugular Reflux Test (negative) & & & \\
\hline Palpation Tip of Heart Blow & & & \\
\hline $\begin{array}{l}\text { Auscultation 3rd intercostal space left parasternal, } \\
\text { parallel pulse scanning }\end{array}$ & & & \\
\hline $\begin{array}{l}\text { Auscultation 2nd intercostal space left and right } \\
\text { parasternal }\end{array}$ & & & \\
\hline Auscultation axilla, carotid artery two-sided & & & \\
\hline $\begin{array}{l}\text { Special auscultation of mitral valve and aortic valve (left } \\
\text { side position and seats) }\end{array}$ & & & \\
\hline Arterial Blood Pressure Measurement (two-sided) & & & \\
\hline
\end{tabular}

\section{Part B}

\begin{tabular}{|l|l|l|l|}
\hline Focus on Examination technique & $\begin{array}{c}\text { insufficient } \\
\text { (0) }\end{array}$ & $\begin{array}{c}\text { moderate } \\
\text { (1) }\end{array}$ & $\begin{array}{c}\text { good } \\
\text { (2) }\end{array}$ \\
\hline Examination technique [Optimal Conditions] & & & \\
\hline Examination technique [Useful order] & & & \\
\hline $\begin{array}{l}\text { Dealing with the patient [salutation, presentation, } \\
\text { friendliness, considerateness] }\end{array}$ & & & \\
\hline $\begin{array}{l}\text { Focus on dealing with the patient [Self-confident } \\
\text { manner] }\end{array}$ & & & \\
\hline
\end{tabular}

Part A of 18 points (equivalent to $70 \%$ )

Part B of 8 points (equivalent to $30 \%$ )

Total Score:

Figure 6: Example of a structured checklist used in the OSCE to assess practical knowledge development

\subsection{Statistical analysis}

Microsoft Office 2016 (Version 16.12, (c Microsoft Corporation, Redmond, USA) and Graphpad Prism 7 for Mac (Graphpad Software (C), La Jolla California, USA) were used for statistical analysis and the graphic display of data.

Long-term theoretical knowledge development within each group was analyzed using the Wilcoxon signedrank test ('Wilcoxon-Test'). Additionally, the Mann-Whitney-U-Test was used to compare the results of the theoretical pre- and post-tests, as well as short-term theoretical knowledge, practical knowledge and student assessments, for both groups. To improve the comparability of test results for the various OSCE scenarios, a specific formula was used to convert percentage ranks into grades ranging from $1=$ "very good" to $6=$ "poor".

\section{Results}

\subsection{Theoretical Examinations}

In the theoretical post-tests both PAL and VPL students achieved significantly better results than in the pretests (PAL: $p<0.0001 ; \mathrm{VPL}: \mathrm{p}<0.0001 ;$ Table 1).

A comparison between the two groups in the pre-test (58.75\% for PAL and $53.55 \%$ for VPL) showed no significant difference, indicating that the two groups performed similarly in terms of theoretical knowledge at the beginning of the elective $(p=0.0653)$. The theoretical post-test results also showed no significant 
difference between the two groups (95.62\% for PAL and $94.17 \%$ for VPL). This shows that the impact of PAL and VPL on the acquisition of long-term theoretical knowledge was similar.

Item-analysis revealed significant knowledge growth in seven of eight primary care learning objectives in the PAL group and six of eight in the VPL group (Table 1).

In six of the seven short-term theoretical tests, no significant difference was found between PAL and VPL students (Table 2). VPL students outperformed PAL students in the question on the clinical presentation of "dyspnea" $(p=0.0116)$. This case was presented by a different peer-tutor because the regular peer-tutor was ill.

However, considering all seven short tests, VPL students tended to have better results, with an average of $100 \%$ comparing to $80 \%$ in the PAL group.

Table 1: Theoretical Pretest and Posttest in the PAL and VPL

\begin{tabular}{|l|c|c|c|c|c|c|}
\hline Item & PAL pre (\%) & $\begin{array}{c}\text { PAL post } \\
(\%)\end{array}$ & p- value & VPL pre (\%) & $\begin{array}{c}\text { VPL post } \\
(\%)\end{array}$ & p-value \\
\hline Complete test & 58.75 & 95.62 & $<0.0001$ & 53.55 & 94.17 & $<0.0001$ \\
\hline Abdominal pain & 20.00 & 96.67 & $<0.0001$ & 25.56 & 90.00 & $<0.0001$ \\
\hline Hypertension & 91.67 & 96.67 & 0.4531 & 79.44 & 98.33 & 0.1250 \\
\hline Tuberculosis & 46.67 & 93.33 & $<0.0001$ & 37.78 & 98.33 & $<0.0001$ \\
\hline Lower-back pain & 51.67 & 95.00 & $<0.0001$ & 39.44 & 96.67 & $<0.0001$ \\
\hline Dyspnea & 66.67 & 100.00 & 0.0001 & 71.11 & 100.00 & 0.0005 \\
\hline Pregnancy & 60.00 & 85.00 & 0.0029 & 32.78 & 86.67 & $<0.0001$ \\
\hline Headache & 48.33 & 100.00 & $<0.0001$ & 24.44 & 88.33 & $<0.0001$ \\
\hline Diabetes & 85.00 & 98.33 & 0.0156 & 71.67 & 95.00 & 0.0859 \\
\hline
\end{tabular}

Table 2: Results of the short tests in the PAL and VPL

\begin{tabular}{|l|c|c|c|}
\hline Item & $\mathrm{p}$ - value & Average PAL (\%) & Average VPL (\%) \\
\hline All tests & 0.0102 & 80.00 & 100.00 \\
\hline Hypertension & 0.806 & 100.00 & 90.00 \\
\hline Tuberculosis & 0.707 & 80.00 & 80.00 \\
\hline Lower-back pain & 0.888 & 80.00 & 90.00 \\
\hline Dyspnea & 0.011 & 80.00 & 100.00 \\
\hline Pregnancy & 0.180 & 100.00 & 100.00 \\
\hline Headache & 0.188 & 90.00 & 100.00 \\
\hline Diabetes & 0.139 & 80.00 & 100.00 \\
\hline
\end{tabular}

\subsection{Student Evaluations}

Students from both study groups assessed their learning experience positively, with most students rating their general learning progress as either "very good" or "good" after course completion (Table 3).

Furthermore, both groups rated the comprehensibility of their seminars as high (Median 1) and the amount of content as appropriate for the given time period (Table 3). No difference was found between PAL and VPL seminars.

However, significant differences between PAL and VPL students were found in answers to control questions, with VPL students reporting "I don't know more than before the lesson", and thus indicating a lower learning effect in five out of eight cases.

When asked to rate the seminars using school grades ( 1 being "very good" to 6 being "unsatisfactory"), students gave the PAL seminar an average grade of 1.6, and the VPL seminar an average of 2.1. 
Table 3: Course evaluation and self-assessment of the PAL and VPL

\begin{tabular}{|c|c|c|c|c|c|c|c|c|c|c|c|c|c|c|c|}
\hline \multirow[t]{2}{*}{ Item } & \multicolumn{3}{|c|}{$\begin{array}{l}\text { "I would rate the } \\
\text { seminar with the } \\
\text { school grade ..." } \\
\text { (1=very good; } \\
6=\text { failed) }\end{array}$} & \multicolumn{3}{|c|}{$\begin{array}{l}\text { "I learned a lot in } \\
\text { this seminar." }\end{array}$} & \multicolumn{3}{|c|}{$\begin{array}{c}\text { "I was able to } \\
\text { follow the patient } \\
\text { case." }\end{array}$} & \multicolumn{3}{|c|}{$\begin{array}{l}\text { "I don't know } \\
\text { more than } \\
\text { before." }\end{array}$} & \multicolumn{3}{|c|}{$\begin{array}{c}\text { "The quantity of } \\
\text { content was } \\
\text { appropriate." }\end{array}$} \\
\hline & $\begin{array}{c}\text { PA } \\
\mathrm{L}\end{array}$ & $\begin{array}{l}\text { VP } \\
\mathrm{L}\end{array}$ & $\begin{array}{c}\mathrm{p}- \\
\text { value }\end{array}$ & $\begin{array}{c}\text { PA } \\
\text { L }\end{array}$ & $\begin{array}{l}\text { VP } \\
\mathrm{L}\end{array}$ & $\begin{array}{c}p- \\
\text { value }\end{array}$ & $\begin{array}{l}\text { PA } \\
\mathrm{L}\end{array}$ & $\begin{array}{l}\text { VP } \\
\mathrm{L}\end{array}$ & $\begin{array}{c}\mathrm{p}- \\
\text { value }\end{array}$ & $\begin{array}{l}\text { PA } \\
\text { L }\end{array}$ & $\begin{array}{l}\text { VP } \\
\mathrm{L}\end{array}$ & $\begin{array}{c}\mathrm{p}- \\
\text { value }\end{array}$ & $\begin{array}{c}\text { PA } \\
\text { L }\end{array}$ & $\begin{array}{l}\text { VP } \\
\mathrm{L}\end{array}$ & $\begin{array}{c}\mathrm{p}- \\
\text { value }\end{array}$ \\
\hline $\begin{array}{l}\text { Abdominal } \\
\text { pain }\end{array}$ & 1 & 2 & $\begin{array}{c}0.083 \\
7\end{array}$ & 2 & 2 & $\begin{array}{c}0.535 \\
0\end{array}$ & 1 & 2 & $\begin{array}{c}0.312 \\
8\end{array}$ & 6 & 5 & 0.143 & 2 & 1 & $\begin{array}{c}0.637 \\
4\end{array}$ \\
\hline $\begin{array}{c}\text { Hypertensio } \\
n\end{array}$ & 2 & 2 & $\begin{array}{c}> \\
0.999 \\
9\end{array}$ & 2 & 2 & $\begin{array}{c}0.260 \\
4\end{array}$ & 1 & 1 & $\begin{array}{c}0.895 \\
3\end{array}$ & 5.5 & 5 & $\begin{array}{c}0.087 \\
6\end{array}$ & 1.5 & $\begin{array}{l}1 . \\
5\end{array}$ & $\begin{array}{c}> \\
0.999 \\
9\end{array}$ \\
\hline $\begin{array}{c}\text { Tuberculosi } \\
\mathrm{s}\end{array}$ & 1 & 1 & $\begin{array}{c}> \\
0.999 \\
9\end{array}$ & 2 & 1 & $\begin{array}{c}0.184 \\
5\end{array}$ & 1 & 1 & $\begin{array}{c}0.549 \\
7\end{array}$ & 6 & 5 & $\begin{array}{c}0.096 \\
3\end{array}$ & 2 & 1 & $\begin{array}{c}0.517 \\
4\end{array}$ \\
\hline $\begin{array}{l}\text { Lower- back } \\
\text { pain }\end{array}$ & 1.5 & 2 & $\begin{array}{c}0.898 \\
7\end{array}$ & 1.5 & 2 & $\begin{array}{c}0.508 \\
4\end{array}$ & 1 & 1 & $\begin{array}{c}0.181 \\
8\end{array}$ & 6 & 5 & $\begin{array}{c}0.008 \\
0\end{array}$ & 1 & 1 & $\begin{array}{c}0.842 \\
8\end{array}$ \\
\hline Dyspnea & 2 & 2 & $\begin{array}{c}0.714 \\
6\end{array}$ & 2 & 2 & $\begin{array}{c}0.356 \\
6\end{array}$ & 1 & 1 & $\begin{array}{c}0.241 \\
1\end{array}$ & 6 & 4 & $\begin{array}{c}0.005 \\
9\end{array}$ & 2 & 1.5 & $\begin{array}{c}0.522 \\
2\end{array}$ \\
\hline Headache & 1 & 2 & $\begin{array}{c}0.140 \\
8\end{array}$ & 1 & 1 & $\begin{array}{c}> \\
0.999 \\
9\end{array}$ & 1 & 1 & $\begin{array}{c}0.630 \\
8\end{array}$ & 6 & 5.5 & 0.110 & 1 & 1 & $\begin{array}{c}0.573 \\
5\end{array}$ \\
\hline Pregnancy & 2 & 2 & $\begin{array}{c}0.166 \\
6\end{array}$ & 2 & 1.5 & $\begin{array}{c}0.025 \\
4\end{array}$ & 1 & 1 & $\begin{array}{c}0.007 \\
6\end{array}$ & 5 & 5 & $\begin{array}{c}0.598 \\
3\end{array}$ & 1 & 1 & $\begin{array}{c}> \\
0.999 \\
9\end{array}$ \\
\hline Diabetes & 1 & 2 & $\begin{array}{c}0.235 \\
3\end{array}$ & 2 & 2 & $\begin{array}{c}0.395 \\
5\end{array}$ & 1 & 1 & $\begin{array}{c}0.761 \\
0\end{array}$ & 6 & 4 & $\begin{array}{c}0.003 \\
8\end{array}$ & 1 & 1 & $\begin{array}{c}0.346 \\
1\end{array}$ \\
\hline
\end{tabular}

\subsection{Practical Examinations}

Students in the PAL and VPL showed no significant difference in their ability to perform a symptom-orientated physical examination and take a medical history $(p=0.1415)$. On average, PAL students obtained $80.26 \%$ and VPL students $79.30 \%$ in the SP OSCE (Table 4).

Item analysis showed no significant difference in any of the four OSCE items, medical history taking $(p=0.1545)$, giving feedback $(p=0.6420)$, abdominal examination $(p=0.8709)$ and cardiac/ or pulmonary examination $(p=0.3462)$ (Table 4).

Table 4: OSCE results of the VPL and PAL groups

\begin{tabular}{|c|c|c|c|c|c|}
\hline & $\begin{array}{l}\text { Medical history } \\
\text { taking }\end{array}$ & Feedback & $\begin{array}{l}\text { Abdominal } \\
\text { examination }\end{array}$ & $\begin{array}{l}\text { Cardiac/ } \\
\text { pulmonary } \\
\text { examination }\end{array}$ & Average results \\
\hline PAL average \% & 86.76 & 69.50 & 93.27 & 91.02 & 80.26 \\
\hline VPL average \% & 84.30 & 72.11 & 87.68 & 84.10 & 79.30 \\
\hline PAL average grade & 1.35 & 2.7 & 1.15 & 1.25 & 1,6 \\
\hline VPL average grade & 1.63 & 2.47 & 1.37 & 1.63 & 1,78 \\
\hline
\end{tabular}

\section{Discussion}

The aim of this study was to compare for the first time VPL and PAL with respect to the acquisition of basic medical knowledge at a student-run free clinic. Overall, our results revealed no significant difference between the teaching formats in terms of long-term increase in theoretical knowledge, and the acquisition of practical skills, when examined using an OSCE. The students also evaluated the quality, content and comprehensibility of PAL and VPL seminars similarly. 
A significant difference in favor of the VPL group was found in short-term theoretical knowledge, while selfassessed learning progress was perceived to be higher in PAL seminars.

\subsection{Theoretical Examinations}

The results of the theoretical post-test, in which both groups showed an overall increase in knowledge of almost $40 \%$ and performed almost equally ( $P A L=95.62 \%, \mathrm{VPL}=94.17 \%$ ), indicate that the use of $\mathrm{VPL}$ is as effective for teaching basic medical knowledge as the PAL that is often used at student-run clinics (Burke et al., 2007; Choudhury et al., 2014; Seifert et al., 2015). Furthermore, a comparison of short-term theoretical test results to post-test results showed almost no loss in performance in either group over a period of six weeks, indicating that teaching quality and comprehensibility were high in both seminars.

Since the post-test was used as a graded examination in the SP elective, students most probably wanted to perform well, which may have influenced the results of the long-term theoretical test.

Previous studies have identified a clear correlation between the type of student assessment and resulting student performance. This was found to be particularly true for summative assessments such as the long-term theoretical test, which tend to show an increase in student performance regardless of the prior training format (Raupach et al., 2013).

There may be several reasons for the significant difference in short-term theoretical knowledge in favor of the VPL group. In the VPL cases, students could navigate freely within the patient case. They also had hyperlink functions to further literature. Furthermore, it should be borne in mind that the PAL case seminars were generally two hours long, whereas the VPL seminars had no time restriction. Therefore, students automatically had more time to become familiar with the topic. Students may therefore have spent more time working on VPL cases than students who had to solve the same case with time constraints (Gunning and Fors, 2012). The tests themselves involved no time restriction, regardless of seminar type. Future tests of VPL cases should therefore include time and content restrictions.

A phenomenon called the testing effect (Kromann, Jensen and Ringsted, 2009) may also explain the better short-term performance of the VPL group. When working on VPL cases, students had to answer many singlechoice questions that were similar to those in the examination that followed the seminar. This may have contributed to the measured performance differences.

\subsection{Practical Examinations}

The OSCE results showed no significant difference in medical case history taking and physical examination skills between students trained using virtual patients and those trained by peer tutors, indicating that the use of virtual patients is as effective for teaching clinical skills as peer-led seminars. The use of multimedia content in the VPL cases, such as video footage of physical examinations and clinical competencies, may have compensated for the absence of a patient and the practice in examination techniques that is regularly used in PAL seminars. But it should be taken into consideration that both groups received the same practical training in the first module of the electives in order to ensure the quality of treatment was acceptable when examining real patients in the SP consultation hour for the first time.

On the other hand, several studies confirm the usefulness of VPL in the acquisition of clinical skills. Parsons et al. (2008) and Triola et al. (2006), found that virtual patients can improve students' communication and clinical skills. Moreover, practicing history taking skills in VPL cases is also well regarded by students (Deladisma et al., 2008; Huang, Reynolds and Candler, 2007;). Nevertheless, further studies are required to investigate the use of VPL in the acquisition of practical (motor-)skills.

\subsection{Student Evaluations}

Students evaluated both VPL and PAL seminars similarly positively in terms of quality, amount of material covered and comprehensibility. However, students in the PAL group self-assessed their learning progress more positively in five out of eight cases. Interestingly, this was not reflected in the theoretical and practical examinations. A possible reason for this difference is the lack of direct oral feedback on student performance from a peer-tutor (i.e. when performing a physical examination or commenting on the case scenario) in the VPL group. Various studies (Archer, 2010; Ruesseler et al., 2017; Van De Ridder et al., 2008) have highlighted 
the importance of structured feedback in undergraduate clinical education. Tworek et al. (2010) found that "virtual patient learning may not produce effective feedback". We tried to include as much written feedback as possible in the VPL seminars, i.e. after completion of single-choice questions. When students answered a question incorrectly, they were given a detailed explanation of what they did wrong and what their possible incorrect reasoning might have been. In addition, further information was provided to enable them to solve the problem. To overcome the disadvantage of a lack of feedback, Tworek et al. (2010) propose "adaptive feedback" with multiple feedback levels, as employed in our VPL cases (e.g. revealing the correct diagnosis step by step, or providing expert opinions).

\subsection{Strengths and limitations of this study}

Various limitations to this study need to be considered when interpreting the results. At forty students, our sample size was relatively small compared to other studies, which might have influenced calculated effect sizes. As mentioned before, the results of the theoretical short-term test may have been influenced by the testing effect (short-term) and by the desire of both study groups to perform well in the summative written examination six weeks after course completion (long-term). This may have led to false-positive results in the theoretical test.

Compared to other studies on the subject, the present study was randomized and controlled to assess the use of VPL as an alternative to PAL on multiple levels. Objective and subjective growth in clinical competence was measured, and the VPL design evaluated, using validated instruments. Furthermore, the knowledge assessment at three points in time over a 14-week period gives a comprehensive overview of learning progress in both teaching interventions.

\section{Conclusion}

Despite its limitations, the originality of this paper should be emphasized. This work is the first to compare the use of VPL and the more traditional teaching method of peer-assisted learning in the context of a student-run free clinic.

The results of this study confirm our earlier hypothesis that VPL seminars are as effective as PAL seminars, and demonstrates that both teaching formats can be used to teach basic medical knowledge and skills in a studentrun free clinic. As only a few randomized controlled trials on VPL and its teaching efficacy exist, it should be mentioned that our study was able to show an increase in both short-term and long-term knowledge. In addition, fundamental practical skills like medical history taking and physical examinations can be taught using VPL cases.

The VPL seminars were well received by students and freedom with respect to the time, place and pace of learning was highly appreciated.

We think that VPLs are a valuable alternative to PAL seminars and are well suited to training medical students to assist at student-run free clinics. However, VPL seminars need to be further adapted and revised to include a more detailed feedback function. Our approach of providing relevant feedback was effective but should be individualized to a greater degree. For example, individualized feedback on the strengths and weaknesses of each student could be given after case completion.

Our VPL cases all had the same linear structure and the students were guided through the case by answering questions and receiving information on the patient. Future studies should examine more complex and branched case formats, even though the development of such VPL cases is likely to be more cost-intensive and difficult to set up.

\section{Acknowledgements}

The authors would like to thank all students involved in the Studentische Poliklinik for their hard work. We also would like to thank Dr. Petra Tiarks-Jungk for her outstanding commitment towards treating underserved patients and her enthusiastic teaching of family medicine. 


\section{References}

Adili, F., Kadmon, M., König, S., and Walcher, F., 2013. Professionalisierung der Lehre im chirurgischen Alltag. Der Chirurg, 84 (10), pp. 869-874.

Archer, J.C., 2010. State of the science in health professional education: effective feedback. Medical Education. 44 (1), pp. 101-108. https://doi.org/10.1111/j.1365-2923.2009.03546.x.

Association of American Medical Colleges (AAMC), 2007. Effective use of educational technology in medical education [pdf]. Available at: <https://members.aamc.org/eweb/upload/Effective\%20Use\%20of\%20Educational.pdf > [Accessed 9 April 2019]

Bryce, D.A., King, N.J., Graebner, C.F., and Myers, J.H., 1998. Evaluation of a diagnostic reasoning program (DxR): exploring student perceptions and addressing faculty concerns. Journal of Interactive Media in Education, 1998 (1), p. 1: https://doi.org/10.5334/1998-1.

Burke, J., Fayaz, S., Graham, K., Matthew, R., and Field, M., 2007. Peer-assisted learning in the acquisition of clinical skills: a supplementary approach to musculoskeletal system training. Medical teacher, 29 (6), pp. 577-582. https://doi.org/10.1080/01421590701469867.

Choudhury, N., Khanwalkar, A., Kraninger, J., Vohra, A., Jones, K., and Reddy, S., 2014. Peer mentorship in student-run free clinics: The impact on preclinical education. Family Medicine, 46 (3), pp. 204-208.

Consorti, F., Mancuso, R., Nocioni, M., and Piccolo, A., 2012. Efficacy of virtual patients in medical education: a metaanalysis of randomized studies. Computers and Education. 59 (3), pp. 1001-1008. https://doi.org/10.1016/j.compedu.2012.04.017.

Cook, D.A., Erwin, P.J., and Triola, M.M., 2010. Computerized virtual patients in health professions education: a systematic review and meta-analysis. Academic Medicine. 85 (10), pp.1589-1602. https://doi.org/10.1097/ACM.0b013e3181edfe13.

Deladisma, A.M., Johnsen, K., Raij, A., Rossen, B., Kotranza, A., Kalapurakal, M., Szlam, S., 4th, J.G.B., Swinson, D., Lok, B., and Lind, D.S., 2008. Medical student satisfaction using a virtual patient system to learn history-taking communication skills. Studies in health technology and informatics. 132, pp. 101-105

Dougiamas, M. and Taylor, P., 2003. Moodle: using earning communities to create an open source course management system. [online] Available at: World Conference on Educaional Media and Technology. 2003, pp. 171-178. Association for the Advancement of Computing in Education (AACE) <https://www.learntechlib.org/primary/p/13739/> [Accessed 9 April 201]

Ellaway, R., 2004. Modeling virtual patients and virtual cases. [pdf] Available at: <https://www.medbiq.org/sites/default/files/files/ModelingVirtualPatientsandVirtualCases_meld.pdf> [Accessed 9 April 2019]

Field, M., Burke, J., Lloyd, D., and McAllister, D., 2004. Peer-assisted learning in clinical examination. Lancet, 363 (9407), pp. 490-491. https://doi.org/10.1016/S0140-6736(04)15501-3.

Field, M., Burke, J.M., McAllister, D., and Lloyd, D.M., 2007. Peer-assisted learning: a novel approach to clinical skills learning for medical students. Medical Education, 41 (4), pp. 411-418. https://doi.org/10.1111/j.13652929.2007.02713.x

Fleetwood, J., Vaught, W., Feldman, D., Gracely, E., Kassutto, Z., and Novack, D., 2000. MedEthEx Online: a computer based learning program in medical ethics and communication skills. Teaching and Learning in Medicine. 12 (2), pp. 96-104. https://doi.org/10.1207/S15328015TLM1202_7

Gormley, G.J., McGlade, K., Thomson, C., McGill, M., and Sun, J., 2011. A virtual surgery in general practice: evaluation of a novel undergraduate virtual patient learning package. Medical Teacher. 33 (10), pp. e522-e527. https://doi.org/10.3109/0142159X.2011.599889

Gunning, W.T. and Fors, U.G., 2012. Virtual Patients for assessment of medical student ability to integrate clinical and laboratory data to develop differential diagnoses: comparison of results of exams with/without time constraints. Medical Teacher. 34 (4), pp. e222-e228. https://doi.org/10.3109/0142159X.2012.642830

Hege, I., Kononowicz, A.A., Berman, N.B., Lenzer, B., and Kiesewetter, J., 2018. Advancing clinical reasoning in virtual patients - development and application of a conceptual framework. GMS Journal for Medical Education, 35 (1), pp. 1-19. https:// doi.org/10.3205/zma001159

Higgs, J., Jensen, G.M., Loftus, S., and Christensen, N., 2018. Clinical reasoning in the health professions. $4^{\text {th }}$ ed. Elsevier Health Sciences.

Huang, G., Reynolds, R., and Candler, C., 2007. Virtualpatient simulation at U.S. and Canadian medical schools. Academic Medicine, 82 (5), pp. 446-451. https://doi.org/10.1097/ACM.0b013e31803e8a0a

Janda, M.S., Mattheos, N., Nattestad, A., Wagner, A., Nebel, D., Färbom, C., Lê, D.H., and Attström, R., 2004. Simulation of patient encounters using a virtual patient in periodontology instruction of dental students:

design, usability, and learning effect in history-taking skills. European Journal of Dental Education. 8 (3), pp. 111-119. https://doi.org/10.1111/j.1600-0579.2004.00339.x

Kononowicz, A.A., Zary, N., Edelbring, S., Corral, J., and Hege, I., 2015. Virtual patients - What are we talking about? A framework to classify the meanings of the term in healthcare education. BMC Medical Education. 15 (1), pp. 1-7. https://doi.org/10.1186/s12909-015-0296-3

Kromann, C.B., Jensen, M.L., and Ringsted, C., 2009. The effect of testing on skills learning. Medical Education. 43 (1), pp. 21-27. https://doi.org/10.1111/j.1365-2923.2008.03245.x 
Kumta, S.M., Tsang, P.L., Hung, L.K., and Cheng, J.C.Y., 2003. Fostering critical thinking skills through a web-based tutorial programme for final year medical students-a randomized controlled study. Journal of Educational Multimedia and Hypermedia. 12 (3), pp. 267-273. Available at: Association for the Advancement of Computering in Education (AACE) <https://www.learntechlib.org/primary/p/11927/> [Accessed 9 April 2019].

Lateef, F., 2018. Clinical Reasoning: The Core of Medical Education and Practice. [pdf] International Journal of Internal and Emergency Medicine. Available at: <http://www.remedypublications.com/international-journalof-internal-andemergency-medicine/articles/pdfs_folder/ijiem-v1-id1015.pdf> [Accessed 9 April 2019].

Marburger Bund (MB), 2017. MB-Monitor 2017. [online] Available at <https://www.marburgerbund.de/bundesverband/themen/marburger-bund-umfragen/mb-monitor-2017> [Accessed 9 April 2019].

Meah, Y.S., Smith, E.L., and Thomas, D.C., 2009. Student-run health clinic: novel arena to educate medical students on system-based practice. Mount Sinai Journal of Medicine. 76 (4), pp. 344-356.https://doi.org/10.1002/msj.20128

Parsons, T.D., Kenny, P., Ntuen, C. a, Pataki, C.S., Pato, M.T., Rizzo, A. a, St-George, C., and Sugar, J., 2008. Objective structured clinical interview training using a virtual human patient. Studies in Health Technology and Informatics, 132, pp. 357-362.

Raupach, T., Brown, J., Anders, S., Hasenfuss, G., and Harendza, S., 2013. Summative assessments are more powerful drivers of student learning than resource intensive teaching formats. BMC Medicine. 11 (1),

p.61. https://doi.org/10.1186/1741-7015-11-61

Ruesseler, M., Sterz, J., Bender, B., Hoefer, S., and Walcher, F., 2017. The effect of video-assisted oral feedback versus oral feedback on surgical communicative competences in undergraduate training. European Journal of Trauma and Emergency Surgery. 43 (4), pp. 461-466. https://doi.org/10.1007/s00068-016-0734-x.

Seifert, L.B., Schaack, D., Jennewein, L., Steffen, B., Schulze, J., Gerlach, F., and Sader, R., 2015. Peer-assisted learning in a student-run free clinic project increases clinical competence. Medical Teacher. 38 (5), pp. 515-522. https://doi.org/10.3109/0142159X.2015.1105940

Siddiqui, S., Siddiqui, S., Mustafa, Q., Rizvi, A.F., and Hossain, I.T., 2018. The benefits of a peer-assisted mock PACES. Clinical Teacher. 15 (3), pp. 221-225. https://doi.org/10.1111/tct.12658

Triola, M., Feldman, H., Kalet, A.L., Zabar, S., Kachur, E.K., Gillespie, C., Anderson, M., Griesser, C., and Lipkin, M., 2006. A randomized trial of teaching clinical skills using virtual and live standardized patients. Journal of General Internal Medicine. 21 (5), pp. 424-429. https://doi.org/10.1111/j.1525-1497.2006.00421.x

Tworek, J., Coderre, S., Wright, B., and McLaughlin, K., 2010. Virtual patients: ED-2 band-aid or valuable asset in the learning portfolio? Academic Medicine. 85 (1), pp. 155-158. https://doi.org/ 10.1097/ACM.0b013e3181c4f8bf

Van De Ridder, J.M.M., Stokking, K.M., McGaghie, W.C., and Ten Cate, O.T.J., 2008. What is feedback in clinical education? Medical Education. 42 (2), pp.189-197. https://doi.org/10.1111/j.1365-2923.2007.02973.x

World Medical Association (WMA), 2013. WMA Declaration of Helsinki - Ethical principles for medical research involving human subjects. [online] Available at: <https://www.wma.net/policies-post/wma-declaration-of-helsinki-ethicalprinciples-for-medical-research-involving-human-subjects/> [Accessed 9 April 2019] 


\section{Appendix}

Supplement : 24-item single-choice test used to assess theoretical knowledge growth

1. Which of the following medications is not used in the eradication therapy of $\mathrm{H}$. pylori gastric mucosal infection?
A) Amoxicillin
B) Clarythromycin
C) Metronidazole
D) Ciprofloxacin
E) Bismuth

2. Your patient, Rudi Racket, has been complaining for weeks about epigastric pain that improves after eating, and very black stool. Diarrhoea and flatulence do not occur. The physical examination is unremarkable, except for epigastric pain. The patient's temperature is $37.2^{\circ} \mathrm{C}$. Your guaiac test is positive. The patient's blood count indicates iron deficiency anaemia. Which further diagnostic measure would be the least effective?

A) $\mathrm{H}$. pylori detection by $13-\mathrm{C}$ breath test

B) Explorative gastro duodenoscopy

C) H. pylori detection by blood culture

D) H. pylori detection by urease rapid test

E) Abdominal Sonography

3. Where is bacterial gastritis most frequently located?

A) Fundus

B) Corpus

C) Antrum

D) Pylorus

E) Bacterial gastritis is equally common in all parts of the stomach.

4. You diagnose primary hypertension in your patient (50 years old, male, BMI: $30.4 \mathrm{~kg} / \mathrm{m}^{2}$, smoker). Which of the following measures is not indicated after the initial diagnosis?

A) Weight reduction

B) Administration of alpha-methyl-DOPA

C) Administration of an ACE inhibitor

D) Smoking cessation

E) Sporting activities

5. Which of the following clinical pictures can cause secondary hypertension?

A) Hypovolaemia

B) Hypothyroidism

C) Carotid sinus syndrome

D) Addison's disease

E) Renal artery stenosis

6 . At what blood pressure level is hypertension (stage 1 ) diagnosed?

A) $>120 / 80 \mathrm{mmHg}$

B) $>80 / 60 \mathrm{mmHg}$

C) $>140 / 90 \mathrm{mmHg}$

D) $>170 / 105 \mathrm{mmHg}$

E) $>180 / 110 \mathrm{mmHg}$

7. Which antibiotics usually belong to the standard treatment of (typical, non-multi-resistant) tuberculosis?

A) Ethambutol + Linezolid

B) Isoniazid + Rifampicin

C) Doxycycline + Ethambutol

D) Pyrazinamide + Levofloxacin

E) Isoniazid + Clindamycin

8. Which statement on the diagnosis and therapy of tuberculosis is correct?

A) The gamma interferon test allows the distinction between latent infection and active disease.

B) The initial tuberculosis infection almost always leads to flu-like symptoms. 
C) Patients with open tuberculosis do not need to be isolated in most cases.

D) Tuberculosis acquired abroad is not subject to reporting obligations.

E) Post-primary tuberculosis may occur when receiving immunosuppressive therapy.

9. Which of the above measures is the least appropriate when open tuberculosis of the lungs is diagnosed in a hospital ward?

A) Isolation of the patient by accommodation in a single room

B) Notification to the responsible health authority

C) Special disposal of waste contaminated with infectious material

D) Immediate BCG vaccination of contact persons that are tuberculin positive

E) X-ray examination of the thorax of contact persons who have undergone tuberculin conversion in the current temporal context.

10. Which of the following does not positively contribute towards deterioration in back pain (so-called "yellowflag")?

A) Heavy physical work in monotonous posture

B) Fever

C) Depression

D) Loss of job

E) Private or professional dissatisfaction

11. Mr. K.M. comes into your medical practice and describes pain around the right lumbar spine that suddenly occurred the day before when lifting a box. After a detailed anamnesis, you learn that the pain is motiondependent and radiates into the thigh. The radiation ends above the knee and the patient does not show any numbness. During the physical examination, you notice pain-related limitation of movement in the lumbar spine, no sensory disturbances or a reduction in strength. Mr. M. is otherwise in good general condition. The symptoms described are highly likely to be what disease?
A) Extraradicular back pain
B) Extravertebral back pain
C) Complicated back pain
D) Uncomplicated back pain
E) Radicular back pain

12. The Ott measure (e.g. Ott $30 / 34 \mathrm{~cm}$ ) is most suitable for assessing the...

A) Bendability of the thoracic spine

B) Stretchability of the thoracic spine

C) Bendability of the lumbar spine

D) Extendability of the lumbar spine

E) Extensibility of the cervical spine

13. You will receive the following laboratory findings: Which form of anaemia is present here and what is the most likely cause?

\begin{tabular}{|l|l|}
\hline Parameter & Values \\
\hline erythrocytes & $4.1 \mathrm{~T} / \mathrm{ml}$ \\
\hline haemoglobin & $9 \mathrm{~g} / \mathrm{dl}$ \\
\hline haematocrit & $30 \%$ \\
\hline $\mathrm{MCV}$ & $73 \mathrm{fl}$ \\
\hline $\mathrm{MCH}$ & $20 \mathrm{pg}$ \\
\hline $\mathrm{MCHC}$ & $27.3 \mathrm{~g} / \mathrm{dl}$ \\
\hline
\end{tabular}
A) Macrocytic hypochromic anaemia - vitamin B12 deficiency
B) Microcytic, hyperchromic anaemia - vitamin B12 deficiency
C) Microcytic hypochromic anaemia - iron deficiency
D) Macrocytic hyperchromic anaemia - iron deficiency
E) Normocytic, normochromic anaemia - vitamin B12 deficiency 
14. What is the most common cause of microcytic hypochromic anaemia?
A) Folic acid deficiency
B) Haemoglobin deficiency
C) Vitamin B12 deficiency
D) Calcium deficiency
E) Iron deficiency

15. What is anaemia often associated with in intrinsic factor deficiency?
A) Bronchial Carcinoma (preneoplasia)
B) Haemolytic anaemia
C) HIV
D) Type A gastritis
E) Crohn's disease

16. In a normal pregnancy, which change in the maternal organism is the least significant?
A) Hyperventilation
B) Training of varicose veins in the vulva and vagina area
C) Increase of the cardiac output per minute
D) Increase of blood lipids
E) Diarrhoea

17. How long does a regular pregnancy last?

A) 36 weeks post menstruationem

B) 38 weeks post menstruationem

C) 40 weeks post menstruationem

D) 40 weeks post conceptionem

E) 42 weeks post menstruationem

18. The most common cause of pregnancy anaemia with haemoglobin levels below $110 \mathrm{~g} / \mathrm{L}$ is:
A) Iron deficiency
B) Latent folic acid deficiency
C) Vitamin B12 deficiency
D) Increased folic acid requirement of the foetus
E) Reduced iron absorption in the intestine

19. and 20. 17-year-old Mrs. Becker comes to you and complains about unilateral headaches that have been going on for six hours now. During that time, your wife would have vomited twice. She also reports that she had "such a flicker in her eye" before the pain began. When asked, she says that the pain is worsened by physical exertion. During the physical examination a clear photophobia is noticeable. The temperature of the Pat. is $36.8^{\circ} \mathrm{C}$.

19. What's the most likely tentative diagnosis...
A) Meningitis
B) Migraine with aura
C) Migraine without aura
D) Tension headache
E) Subarachnoid haemorrhage

20. ... and what immediate therapeutic measures should be considered?

A) I.v. antibiotic treatment with cefotaxime and ampicillin, and additional dexamethasone i.v.

B) Ice bag treatment and application of peppermint oil, as well as relaxation therapy

C) Immediate referral of the patient to the stroke unit via ambulance

D) Treatment with ASS 1000 mg i.v., and additional MCP 20 mg i.v., and Sumatriptan i.n.

E) Migraine prophylaxis with Propanolol $80 \mathrm{mg}$ p.o and Amitryptylin $100 \mathrm{mg}$ p.o

21. A 30-year-old man suffers from recurrent attacks of severe headaches, which subside after 1-2 hours of analgesic therapy. Which of the above symptoms is not part of the suspected diagnosis of cluster headache?

A) Miosis

B) Heavy sweating in the area of the forehead and face

C) Ptosis

D) Rhinorrhea 


\section{E) Photopsia}

22. Type 1 diabetes mellitus differs primarily from type 2 diabetes mellitus:

A) The formation of the glycosylated blood protein $\mathrm{HbA1c}$

B) An increased renal threshold for glucose

C) Postprandial C-peptide concentration in the blood is extremely low despite elevated blood sugar levels

D) A slowing of the nerve conduction speed

E) Pathological blood sugar levels in the oral glucose tolerance test

23. A 57-year-old, symptom-free self-employed master baker measures fasting blood glucose levels of $137 \mathrm{mg} / \mathrm{dL}$ during a routine examination. In the subsequent oral glucose tolerance test, a 2-hour plasma glucose value of $266 \mathrm{mg} / \mathrm{dL}$ was observed. The following findings are also collected: $\mathrm{HbA} 1 \mathrm{c} 63 \mathrm{mmol} / \mathrm{mol}$ $(7.9 \%)$, serum creatinine $0.9 \mathrm{mg} / \mathrm{dL}$, body mass index $33.4 \mathrm{~kg} / \mathrm{m} 2$ Which of the following procedures is the best initial treatment for the patient?

A) Start of a monotherapy with basal insulin

B) Inpatient admission to a diabetes clinic for weight reduction

C) Diabetic training, lifestyle change and prescription of metformin

D) Oral antidiabetic 3-fold combination therapy

E) Start of intensified insulin therapy

24. $12 \% \mathrm{HbA} 1 \mathrm{c}$ was measured for Ms. A. Which of the following statements about this parameter is the most accurate?

A) If the insulin dose is adjusted using $\mathrm{HbA1c}$, it is not necessary to consider blood glucose profiles.

B) The blood glucose setting can be traced back over the last 2-3 months using HbA1c.

C) $\mathrm{HbA1c}$ is formed by the enzymatic binding of glucose to the terminal $\mathrm{COOH}$ group of the haemoglobin alpha chain.

D) $\mathrm{HbA1C}$ is determined with a pulse oximeter.

E) The parameter is not susceptible to disturbing factors. 